Universidade de Brasília - UnB

Faculdade de Economia, Administração, Contabilidade e Ciência da Informação e Documentação (FACE)

Programa de Pós-Graduação em Administração (PPGA)

TALITA CRISTINA PIRES LIMA

\title{
INCLUSÃO DE PESSOAS COM DEFICIÊNCIA AO MUNDO DO TRABALHO
}




\section{TALITA CRISTINA PIRES LIMA}

\section{INCLUSÃO DE PESSOAS COM DEFICIÊNCIA AO MUNDO DO TRABALHO}

Monografia apresentada ao Programa de PósGraduação em Administração da Faculdade de Economia, Administração, Contabilidade e Ciência da Informação e Documentação (FACE), da Universidade de Brasília - UnB, como requisito parcial à obtenção do grau de Especialista em Gestão de Pessoas.

Orientador: Prof. Dr. Marcus Vinicius Soares Siqueira 
"A verdadeira igualdade consiste em se tratar igualmente os iguais e desigualmente os desiguais à medida em que se desigualem ".

Aristóteles 
Dedico

Este trabalho à minha família. 
Agradeço

A Deus, por todas as graças, por minha vida.

Aos meus pais e irmã pela compreensão, carinho e apoio constantes.

Ao professor e orientador, Marcus Vinicuis Soares Siqueira, pela orientação, paciência e estímulo.

Aos meus amigos pela paciência, companheirismo e incentivo.

Aos anjos que me ajudaram a desenvolver e concluir este projeto com suas contribuições especiais Anne Soares, Helvécio Junior, Nathália Albuquerque,

Paloma Galdino e Patícia Araújo. 


\section{RESUMO}

Este estudo teve o objetivo de verificar as dificuldades de inclusão de pessoas com deficiência no mundo do trabalho, descrevendo parte da trajetória e a vivência de uma pessoa com limitações que precisa vencer diariamente barreiras que as impedem de convívio social. A pesquisa buscou apoio em artigos e livros com temas relacionados a trabalho, pessoas com deficiência, diversidade e inclusão. Foi realizada uma pesquisa qualitativa com seis funcionários de uma organização privada sediada em Brasília. Os resultados obtidos foram classificados em 3 categorias: Dificuldades cotidianas e a escolha do profissional; significado do trabalho na vida da pessoa com deficiência; ações inclusivas. A análise dos resultados constatou que o processo de inclusão de pessoas com deficiência está caminhando a passos curtos e mal direcionados, e sugere que a informação e o conhecimento ultrapassem as barreiras socioeconômicas para que o preconceito seja vencido e a igualdade possa prevalecer.

Palavras-chave: Pessoas com deficiência, Diversidade, Inclusão, Preconceito. 


\section{SUMÁRIO}

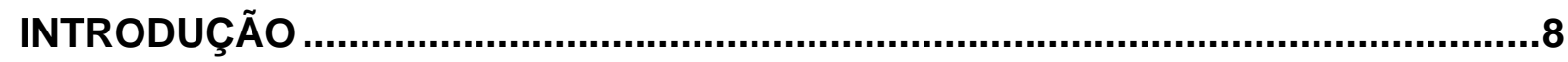

1 REFERENCIAL TEÓRICO .....................................................................12

1.1 Diversidade................................................................................... 12

1.2 Dificuldades, constrangimentos e humilhações....................................14

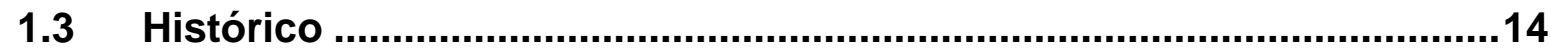

1.3 Legislação e Políticas Afirmativas ............................................................15

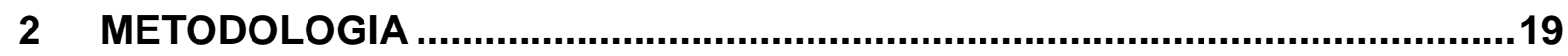

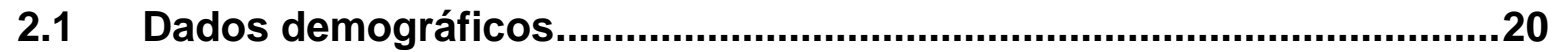

2.2 Instrumento de coleta de dados ........................................................20

2.3 Procedimento de coleta de dados ....................................................21

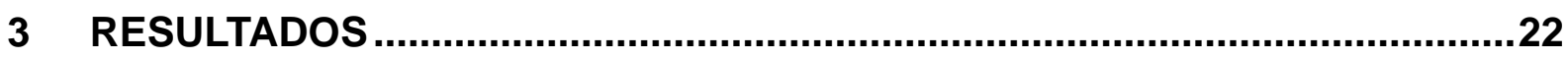

3.1 Dificuldades cotidianas e a escolha do profissional ..........................22

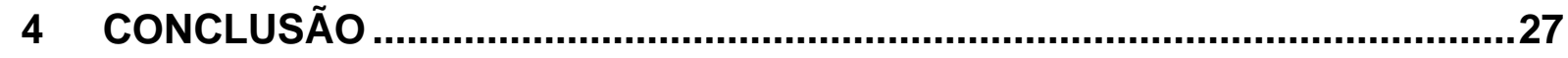

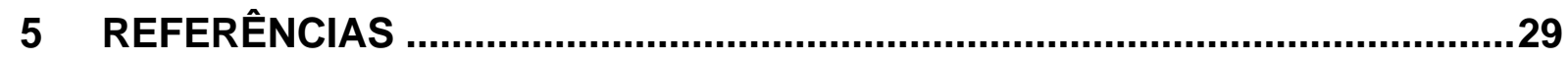




\title{
INTRODUÇÃO
}

O tema da inclusão social dos portadores de deficiência tem ganhado cada vez mais importância nos meios de comunicação e nas metas empresariais, graças ao surgimento de uma sociedade mais consciente e comprometida com o tema, que valoriza e exige o mesmo comprometimento do setor empresarial.

\begin{abstract}
O cenário de mudanças contínuas e aceleradas e a diversidade que caracteriza o mundo globalizado impõe às empresas novos desafios e demandas. Assim, as empresas, além de se preocuparem com seus produtos e clientes, ficam atentas às questões sociais, uma vez que isto é fator decisivo para a competitividade (ALMEIDA; CARVALHO-FREITAS; MARQUES, 2009, p. 55)
\end{abstract}

Ser socialmente responsável não é mais um diferencial competitivo e sim uma necessidade primária, pois o mercado começou a privilegiar produtos de empresas que busquem não apenas a satisfação do consumidor com o produto, mas que também prestem algum serviço à sociedade.

Segundo Ribas (2009, p. 212) "empresas não são organizações filantrópicas. Empresas são organizações nas quais se produz e comercializa bens ou serviços, geram empregos e têm a finalidade de impulsionar o mercado e provocar a circulação e o consumo da riqueza". As empresas têm se preocupando não apenas em incluir pessoas com deficiência em seus quadros funcionais, mas também em torná-los tão produtivos quanto os trabalhadores não-deficientes, por vezes utilizando suas 'limitações' como um diferencial e não como uma restrição funcional.

Surdos e mudos trabalhando em bibliotecas, cegos que trabalham na produção industrial, são pequenos exemplos onde a deficiência é um diferencial competitivo e não uma restrição operacional, o que vem possibilitando que tanto deficientes quanto não-deficientes, que estão em busca de oportunidades de trabalho, no meio de tantas exigências, busquem desenvolver "arquétipo de superherói de modo a buscar ou manter o seu lugar ao sol" (SIQUEIRA; OLIVEIRASIMÕES, 2009, p. 188).

Para dar oportunidades para pessoas com deficiência é preciso vencer o preconceito e acreditar no potencial que cada uma delas têm a oferecer, explorando suas capacidades e respeitando suas limitações. Não é mais possível ver a 
contratação destas pessoas como uma exigência legal, com restrições de custo, prazo e qualidade, cada elemento do processo produtivo deve agregar valor, ou então o produto estará fadado ao fracasso. Assim, segundo Ribas, "Se não acreditarmos que as pessoas com deficiência podem gerar riqueza pelo seu próprio trabalho, é melhor não trazê-las para dentro das empresas" (RIBAS, 2009, p. 212).

A qualificação profissional é necessária a qualquer profissional que deseje progredir em sua carreira, mas até mesmo isso é complexo para uma pessoa com deficiência, pois existem diversos cursos para sua a qualificação inicial, mas poucos treinamentos para a melhoria e especialização desse recém-ingresso no mercado, o que acaba exigindo um esforço a mais, de quem já precisa de diversos esforços extras para sobreviver.

O ingresso de pessoas com deficiência no mundo do trabalho e na sociedade produtiva como um todo, está sendo facilitado graças a iniciativas como a criação das cotas obrigatórias. E nesse sentido, Tanaka e Manzini entendem que "Apesar das leis terem funcionado como uma alavanca impulsionadora da abertura de oportunidades nas empresas, o número de pessoas com deficiência que está participando do mercado de trabalho, ainda é muito aquém do que ela prevê". (TANAKA; MANZINI, 2005, p. 274)

Essas leis representam uma enorme evolução no sentido da inclusão destes trabalhadores na sociedade, mas ainda não resolve o tão complexo problema de exclusão, pois é obstaculizada por diversas dificuldades em atender às necessidades das pessoas com deficiência ${ }^{1}$

Segundo Tanaka e Manzini (2005, p. 292) ainda falta "qualificação profissional e preparo social para que a pessoa com deficiência possa ocupar um cargo cujo perfil seja compatível com as suas habilidades e com as reais necessidades da empresa" e não restringir a estas pessoas, cargos e funções subalternos sem a oportunidade de desenvolvimento.

\footnotetext{
1 Um exemplo são os cadeirantes que precisam de transporte público acessível, espaço para transitarem, banheiros especiais e rampas. Ou seja, a sociedade e as empresas não possuem o mínimo para que estas pessoas exerçam a cidadania.
} 
O estudo pretende evidenciar dificuldades encontradas por pessoas com deficiência em suas trajetórias profissionais na iniciativa privada, identificando estratégias e soluções que simplificariam o processo de inclusão, bem como identificar peculiaridades no processo que facilitaram e agilizaram a inclusão social pretendida.

Apesar da lei já existir a algum tempo, pouco acontece no meio organizacional, muitas das vezes por falta de conhecimento ou desinteresse. $O$ fato é que as empresas precisam adequar as atividades inerentes ao funcionamento de um setor, ou até mesmo de todas essas atividades à esses indivíduos.

No caso de empresas de pequeno porte o custo pode ser extremamente elevado em relação à receita algo que não ocorre em empresas de grande porte. Devido ao grande dinamismo imposto às empresas que atuam em mercados competitivos se torna custoso manter as pessoas com deficiência integrados, atualizados e produtivos.

Assim, por vezes restarão aos funcionários com deficiência, em ambos os casos, um papel meramente decorativo, para atendimento à legislação especifica ou até para se beneficiar da imagem social de ter em seu quadro funcional pessoas com deficiência, constituindo-se assim uma situação que pode se tornar constrangedora e humilhante, pois o indivíduo não se sente nem valorizado e nem produtivo, contribuindo para agravar ainda mais o preconceito à eles infringido. $A$ descaracterização da lei, que deveria integrar o portador, passa a excluí-lo, deixando em voga características preconceituosas que os denegrirem ainda mais.

Nestes processos as empresas deveriam adotar postura consciente promovendo a diversidade e não reproduzir os preconceitos e desigualdades existentes na sociedade (ETHOS, 2000). Para evitar isso é necessário que a seleção de novos talentos com deficiência seja feita com critérios que permitam que esses indivíduos trabalhem de forma efetiva, se enquadrando e agregando valor ao seu posto de trabalho.

A criação de postos de trabalho sem significação real dentro de instituições também é um grande problema, pois os ocupantes destas vagas por um lado não se sentem a necessidade de progredir e por outro essa chance não existe, 
uma vez que o posto serve apenas para cumprir a cota. Medidas como o desligamento de profissionais que não cumpram com o esperado para seu cargo e a promoção dos ocupantes e por vezes procrastinada, dado o alto custo de contratação e alocação, passando pela adequação de mobiliário à treinamento de colaboradores.

A erradicação ou amenização do preconceito é um dos fatores que motivaram à criação de tópicos específicos nas leis 8.112 e 8.213/91 focando especificamente a integração e sociabilização dos indivíduos com deficiência, por meio do trabalho, mas que dada a função decorativa que eles, em alguns casos, assumem em parte das empresas que os contratam, nota-se que a instituição dessas leis foi benéfica, mas ainda precisa ser ajustada e absorvida pelas organizações e pelos demais funcionários dessas, é preciso levar em consideração outros fatores, pois questão da inserção da pessoa com deficiência no mercado de trabalho envolve inúmeros aspectos de ordem social, ambiental, econômica, cultural, política, ética moral e outros (ETHOS, 2000).

A inclusão de portadores de deficiência no mundo do trabalho, ainda tem pouco espaço nos estudos, debates sociais e na mídia. Informação é a principal ferramenta para tornar possível a verdadeira inclusão e sociabilização não só de pessoas com deficiência, que caracterizam uma das minorias, dentro de tantas outras que também precisam de tanta atenção quanto.

A diversidade vista por muitos como fonte de conhecimento, inovação e criatividade ainda é ignorada e taxada como motivo de preconceito e discriminação a tudo que foge de um padrão inexistente. Muitos não enxergam a diversidade como algo positivo e importante, mas como motivo de preconceito e exclusão. A falta de conhecimento é a principal causa da discriminação que ocorre com as minorias do país. Não só os portadores de deficiência, mas todos aqueles que não estão de acordo com o estereótipo padrão sofrem com o preconceito.

A pesquisa visa evidenciar as dificuldades de inclusão e adaptação ao mundo do trabalho do ponto de vista das pessoas com deficiência. Mostrar as dificuldades encontradas no meio profissional e pessoal e a superação destas. 


\section{REFERENCIAL TEÓRICO}

\subsection{Diversidade}

A garantia e observância a diversidade representa um princípio básico de cidadania que asseguram condições de desenvolvimento de seus talentos e potencialidades em meio a sociedade. A prática da diversidade é o direito a diferença. Para que aconteça essa prática é necessário oferecer condições e ambientes em que as pessoas tenham liberdade de agir conforme seus valores individuais (ETHOS, 2000).

Não se pode deixar de lado a análise e a gestão de conflitos que isso venha a gerar. Para o ser humano é muito difícil se adaptar com o que é diferente. Por isso o preconceito e a discriminação estão enraizadas num país como o Brasil que é berço de uma das maiores diversidades, cultural, racial e sócio-política, surgida no momento inicial de concepção da colônia, com a miscigenação de diversas raças e credos, européias e africanas, e perpetuadas até o hoje, com a aceitação e produção cultural própria, onde até mesmo elementos culturais importados, são modificados e adaptados e bem vindos.

Segundo o Instituto Ethos (2000, p. 12) é fundamental que se pratique e valorize a diversidade são ações que traduzem no combate ao preconceito e à discriminação. Facilmente se é verificado que a afirmação é valida, no entanto se torna complexo o combate visto que estes problemas são mascarados e até mesmo incentivados a não demonstração tendo em vista os efeitos que possa gerar. Daí trazer mudanças efetivas para a aceitação de culturas, comportamentos, hábitos e rotinas se torna complexo e muitas vezes sem fundamento (ETHOS, 2000).

É necessário trabalhar a educação desde cedo para tornar viável a aceitação da diversidade, pois viver em um ambiente de discriminação pode reprimir talentos e comprometer a capacidade não só da empresa mas de uma sociedade de reconhecer adequadamente o desempenho daqueles que de certa forma estão fora dos padrões (ETHOS, 2000). 
As oportunidades precisam ser melhor distribuídas, vivemos em uma sociedade estratificada, em que o acesso à educação e às posições de prestígio no mercado de trabalho são definidas pelas origens econômica e racial (FLEURY, 2000)

Muito se fala sobre diversidade, mas pouco se sabe ao certo o que é. Nesse sentido, Fleury (2000) conceitualiza que:

A diversidade é definida como um mix de pessoas com identidades diferentes interagindo no mesmo sistema social. Nesses sistemas, coexistem grupos de maioria e de minoria. Os grupos de maioria são os grupos cujos membros historicamente obtiveram vantagens em termos de recursos econômicos e de poder em relação aos outros.

A gestão da diversidade tem como um dos principais objetivos a administração das relações de trabalho e a composição interna da força de trabalho desta forma seleciona e retendo os melhores talentos dentre todas as camadas sociais incluindo os chamados grupos de minoria (FLEURY, 2000)

O futuro é promissor, mas depende de empenho e vontade das organizações de efetivarem planos de inclusões e a ação efetiva da diversidade, podendo dessa forma atrair e desenvolver novas competências e talentos, agregando valor e obtendo cada vez mais êxito no competitivo mercado global (FLEURY, 2000).

Em uma sociedade com graves problemas de injustiça, em diversos aspectos, como a brasileira, não há como não defender que a valorização da gestão da diversidade. Tal gestão teria um aspecto altamente positivo por representar iniciativas promissoras de inclusão social, fazendo com que as minorias deixem de viver a margem da sociedade e passem a integrar o convívio social (FLEURY, 2000).

As empresas, entretanto, precisam ser menos ideológicas e mais estratégicas, para que os projetos em questão saiam do papel e integrem suas políticas de trabalho (FLEURY, 2000). Não é possível e nem viável se manter em uma empresa um contingente de elementos que apenas sirvam para cumprir um cotismo legislacional, é necessário desmistificar o uso desse contingente improdutivo, tornando-o uma vantagem competitiva, explorando as virtudes e respeitando as restrições impostas a cada um. 


\subsection{Dificuldades, constrangimentos e humilhações}

Para Siqueira, "Humilhação é sofrimento que fere a vítima, que ataca a sua interioridade e a sua autonomia, fazendo com que o sujeito tenha diminuída a sua auto-estima" (SIQUEIRA; OLIVEIRA-SIMÕES, 2009, p. 188).

Boa aparência, que vai além da boa apresentação, são considerados atributos imprescindíveis na maioria processos seletivos, em alguns casos chega a sobre sair as habilidades do candidato. As pessoas com deficiência são frequentemente preteridas nestes tipos processos que podem ser considerados ilegais e injustos (SIQUEIRA; OLIVEIRA-SIMÕES, 2009).

O governo garante, por meio das leis, a inclusão de pessoas com deficiência no mercado de trabalho, mas não oferece a qualificação profissional para que essas pessoas concorram de maneira igual aos demais, contribuindo para a discriminação dos selecionadas, uma vez que poderão ser contratados por imposição legal e não por possuir competências e habilidades requeridas pelas organizações (SIQUEIRA; OLIVEIRA-SIMÕES, 2009).

Mas o processo não precisa ser assim, uma pessoa com deficiência deve ser encarada como um pessoal com características peculiares, que geram habilidades e restrições também peculiares. A qualificação profissional precisa ser melhor distribuída para que essas pessoas se tornem tão capazes profissionalmente quanto as demais que concorrem no mundo do trabalho.

\subsection{Histórico}

Segundo Almeida (2009), a inserção de pessoas com deficiência no mercado formal de trabalho, se configura de forma recente, pois o direito delas ao trabalho foi legalizado somente após a Segunda Guerra Mundial, em razão dos excombatentes que voltavam mutilados (ALMEIDA; CARVALHO-FREITAS; MARQUES, 2009, p. 58).

Assistir às pessoas com deficiência de modo paternalista foi, por muitas gerações, a resposta encontrada, para manter estas pessoas afastadas da 
sociedade. O que desconsidera por completo suas potencialidades e impossibilita de viver em sociedade (DIAS, 2002).

Contudo, a partir das décadas de 1960 e 1970 essa postura assistencialista passou a ser questionada pelos movimentos sociais, especialmente nos Estados Unidos e no Reino Unido. Estes movimentos contribuíram para uma nova perspectiva ideológica relacionada às pessoas com deficiência, com forte ênfase nos direitos civis e para uma nova definição de deficiência, que passa a considerar os aspectos sociais - para além de uma imitação individual, a deficiência também seria determinada pelas falhas da sociedade em acomodar as necessidades das pessoas que as possuem (ALMEIDA; CARVALHO-FREITAS; MARQUES, 2009,p. 58)

No Brasil a questão demorou a preocupar os nossos governantes, a pessoa com deficiência, como se pode imaginar, sempre esteve, e continua a estar, à margem da participação desejada e verificada em países desenvolvidos. A legislação contribuiu para a melhora mínima deste quadro mas ainda falta muito a ser feito. O país sair da ignorância neste sentido e atuar de maneira igualitária com toda a população (DIAS, 2002).

\subsection{Legislação e Políticas Afirmativas}

A lei $\mathrm{n}^{\circ} 10.098$ de 19 de dezembro de 2000 garante as pessoas com deficiência o direito a acessibilidade e a define como a possibilidade e condição de alcance para utilização, com segurança e autonomia, dos espaços, mobiliários e equipamentos urbanos, das edificações, dos transportes e dos sistemas e meios de comunicação, por pessoa portadora de deficiência ou com mobilidade reduzida. Sabemos que a lei é infringida em vários momentos onde existem as barreiras que lei também as define e classifica como:

[...] qualquer entrave ou obstáculo que limite ou impeça o acesso, a liberdade de movimento e a circulação com segurança das pessoas" classificadas em:

a) barreiras arquitetônicas urbanísticas: as existentes nas vias públicas e nos espaços de uso público;

b) barreiras arquitetônicas na edificação: as existentes no interior dos edifícios públicos e privados;

c) barreiras arquitetônicas nos transportes: as existentes nos meios de transportes; 
barreiras nas comunicações: qualquer entrave ou obstáculo que dificulte ou impossibilite a expressão ou o recebimento de mensagens por intermédio dos meios ou sistemas de comunicação, sejam ou não de massa;"

Estas inúmeras barreiras representam a gravidade da dificuldade de acesso das pessoas com deficiência não só ao mercado de trabalho, mas a todos os locais e informações procurados no cotidiano (DIAS, 2002). As tentativas de inclusão e sociabilização de pessoas com deficiências, ficam ainda mais comprometidas ao se deparar com os obstáculos existentes. Como se pode querer que as pessoas com deficiência que já vivem a margem da sociedade estejam presentes exercendo sua cidadania se não lhe é dado a oportunidade para isso. O preconceito é a completa falta de conhecimento sobre o assunto e é uma barreira não reconhecida por aqueles que acreditam que ele não existe.

Uma maneira de combater a discriminação foi à criação das cotas obrigatórias nos quadros funcionais, tanto na esfera pública, quanto na privada. No âmbito das instituições públicas, a Lei no 8.112, em seu Artigo $5^{\circ}$, no $\S 2^{\circ}$, garante que nos concursos públicos até $20 \%$ das vagas devem ser destinadas aos portadores de necessidades especiais.

Tal determinação não garante e nem determina um quantitativo mínimo desses, nos quadros funcionais, como é feito pela lei 8.213/91, por meio do Artigo 93, que visa empresas privadas, determinando percentagens mínimas relacionadas ao número de funcionários efetivos.

Assim, empresas que possuam de 100 a 200 empregados - 2\% do quadro de empregados efetivos, obrigatoriamente, precisam ser de portadores de necessidades especiais; de 201 até 500 empregados - 3\%; de 501 até 1000 empregados - 4\%; mais de 1000 empregados - 5\%. As empresas que descumprem esta lei, quando autuadas, pagam multas que variam de $\mathrm{R} \$ 1.195,13$ a $\mathrm{R} \$$ 119.512,33, conforme a Portaria 1.199, de 28 de outubro de 2003. A fiscalização ainda é pequena tendo em vista a quantidade de empresas que preferem seguir pela ilegalidade.

Vale ressaltar que a criação dessa lei vai além da criação de novos postos de trabalho e a obrigatoriedade da contratação de pessoas com deficiências, a 
norma possui outro atributo, qual seja, o de incentivá-los a saírem às ruas, de reintroduzi-los na sociedade, de propiciar o seu aperfeiçoamento sócio-cultural, incentivando-os a melhorar o seu potencial, a aprimorar suas qualidades, superando as barreiras que a sociedade lhes impõe.

É razoável concluir que houve muitos avanços legislativos no Brasil e se ter um nível significativo de proteção legal para deficientes, mas ainda se faz necessário que se ponham em prática muitas dessas propostas legais. Vale dizer que são observados poucos avanços culturais e sociais no trato do problema (DIAS, 2002).

Estas medidas compensatórias nada mais são do que as chamadas ações afirmativas, as quais, segundo Gomes (apud SILVA FILHO, 2005):

[...] nada mais são do que tentativas de concretização da igualdade substancial, sendo possível conceituar as ações afirmativas como sendo, um conjunto de políticas públicas e privadas de caráter compulsório, facultativo ou voluntário, concebidas com vistas ao combate à discriminação racial, de gênero e de origem nacional, bem como para corrigir os efeitos presentes da discriminação praticada no passado, tendo por objetivo a concretização do ideal de efetiva igualdade de acesso a bens fundamentais como a educação e o emprego.

São medidas que visam basicamente corrigir distorções sociais, raciais e culturais, onde uma determinada parcela domina as demais, seja pela força, pela quantidade de participantes, enfim são medidas que visam tornar a sociedade mais justa e com menores diferenças entre os membros.

O Decreto n. 914/93, o qual instituiu a Política Nacional para a Integração da Pessoa portadora de Deficiência, tem como uma de suas diretrizes (art. $5^{\circ}$ ), "promover medidas que visem a criação de empregos que privilegiem atividades econômicas de absorção de mão-de-obra de pessoas portadoras de deficiência, assim como proporcionar ao portador de deficiência qualificação e incorporação no mercado de trabalho".

Já a Portaria n. 772, de 26.8.99, do Ministério do Trabalho, permite a contratação de pessoa deficiente, sem a caracterização de emprego com o tomador de serviços, quando:

a) realizada com a intermediação de entidade sem fins lucrativos, de natureza filantrópica e de comprovada idoneidade, que tenha por objeto 
assistir o portador de deficiência; b) a entidade assistencial intermediadora comprove a regular contratação de portadores de deficiência nos moldes da Consolidação das Leis Trabalhistas; c) o trabalho destinar-se a fins terapêuticos, desenvolvimento da capacidade laborativa reduzida devido a deficiência, ou inserção da pessoa portadora de deficiência no mercado de trabalho e d) igualdade de condições com os demais trabalhadores, quando os portadores de deficiência estiverem inseridos no processo produtivo da empresa (art. $\left.1^{\circ}\right)$.

O trabalho prestado pela pessoa portadora de deficiência física poderá ocorrer no âmbito da entidade que prestar assistência ou da empresa que para o mesmo fim celebrar convênio ou contrato com a entidade assistencial $\left(\operatorname{art.~} 1^{\circ}, \S 1^{\circ}\right)$.

Essa prática, como diversas outras no Brasil, foi por vezes prejudicada e teve sua reputação manchada, por ser utilizada como artifício para a contratação de empregados burlando a legislação trabalhista vigente, problema esse, em tese, solucionado pelo Enunciado n. 331, do Tribunal Superior do Trabalho:

IV - O inadimplemento das obrigações trabalhistas, por parte do empregador, implica a responsabilidade subsidiária do tomador dos serviços, quanto àquelas obrigações, inclusive quanto aos órgãos da administração direta, das autarquias, das fundações públicas, das empresas públicas e das sociedades de economia mista, desde que hajam participado da relação processual e constem também do título executivo judicial (art. 71 - da Lei $n^{\circ}$ 8.666, de 21.06.1993)

No âmbito da União, é assegurado o direito da pessoa portadora de deficiência se inscrever em concurso público para provimento de cargos cujas atribuições lhe sejam compatíveis e reservado até $20 \%$ das vagas oferecidas no concurso (art. 50, § $2^{\circ}$, Lei n. 8.112/90).

Além disso, o Poder Executivo Federal estabelecerá, na forma da lei e ouvido o Conselho Nacional de Seguridade Social, mecanismos de estímulo às empresas que utilizem empregados de deficiência física, sensorial ou mental, com desvio do padrão médio (art. 22, § 4º , Lei n. 8.212/91). 


\section{METODOLOGIA}

Foi efetuada uma pesquisa qualitativa, que segundo Günther (2006), há aceitação explícita da influência de crenças e valores sobre a teoria, sobre a escolha de tópicos de pesquisa, sobre o método e sobre a interpretação de resultados.

A pesquisa teve caráter exploratório, uma vez que ainda há pouco estudo sobre o tema inclusão de pessoas com deficiência no mundo do trabalho. O método escolhido foi por desejo de se inferir do respondente, com maior riqueza de detalhe, suas percepções e vivências relacionadas a inclusão no mundo do trabalho.

A pesquisa foi efetuada em Brasília, na sede de em uma multinacional do ramo de tecnologia da informação de origem brasileira a qual será denominada "Delta" para fins deste estudo.

Trata-se de uma organização que demonstra preocupação com o social, oferece cursos e treinamentos a comunidade carente e também para deficientes visuais e auditivos, com ajuda de voluntários que podem ser ou não funcionários da mesma. A proposta é que os melhores alunos dos cursos sejam incluídos em seu quadro funcional e efetivo.

Sabe-se que a Delta trabalha com as seguintes modalidades de contratos em sua organização:

CLT (Consolidação das Leis do Trabalho ); PJ (Pessoa Jurídica); Jovem Aprendiz (Contratação temporária com registro em carteira vinculada a curso externo); Terceirizados (Contrato de empresas prestadoras de serviços).

Para fins desta pesquisa os funcionários analisados são contratados em regime CLT (2 respondentes) e Jovem Aprendiz (4 respondentes). A maioria (5) destes possui deficiência auditiva e para melhor entendimento a pesquisa foi realizada com ajuda de um intérprete. As entrevistas foram aplicadas durante o mês de AGOSTO/2009. 
O critério para a participação na pesquisa foi relacionado as características do indivíduo - Pessoas com deficiência, e pela facilidade para a coleta de dados.

Todos os respondentes possuem o ensino médio completo, têm a idade entre 19 e 35 anos; a maioria (4) possui entre 19 e 22 anos e pertence ao sexo feminino (5); todos trabalham em funções administrativas. Por questões de contrato, a maioria (4) tem pouco tempo na organização. O resumo destas informações está no quadro de dados demográficos.

\subsection{Dados demográficos}

As informações que contemplam o grupo de respondentes que fizeram parte da entrevista objeto deste estudo compreendem, de forma resumida, o seguintes dados demográficos:

\begin{tabular}{|c|c|c|c|c|c|}
\hline Entrevistado & $\begin{array}{c}\text { Situação } \\
\text { contratual }\end{array}$ & Formação & Sexo & Idade & $\begin{array}{c}\text { Tempo de } \\
\text { empresa }\end{array}$ \\
\hline 1 & CLT & Ensino médio & Feminino & 29 & 6 anos \\
\hline 2 & Jovem aprendiz & Ensino médio & Feminino & 19 & 7 meses \\
\hline 3 & Jovem aprendiz & Ensino médio & Feminino & 20 & 7 meses \\
\hline 4 & Jovem aprendiz & Ensino médio & Feminino & 20 & 7 meses \\
\hline 5 & Jovem aprendiz & Ensino médio & Feminino & 22 & 7 meses \\
\hline 6 & CLT & Ensino médio & Masculino & 35 & 6 anos \\
\hline
\end{tabular}

FONTE: PESQUISA DE CAMPO/AUTORA

\subsection{Instrumento de coleta de dados}

Foi utilizada a técnica de entrevista individual, tendo em vista a natureza pessoal e reservada do assunto tratado e a pretensão de maximizar a oportunidade de compreender as diferentes percepções dos entrevistados (GASKELL, 2002 p.69).

Quanto às entrevistas, estas foram realizadas na própria empresa Delta, as quais estavam sempre condicionadas à disponibilidade dos respondentes, os quais eram comunicados e convidados antecipadamente. 


\subsection{Procedimento de coleta de dados}

A pesquisa teve autorização prévia da empresa. As entrevistas foram realizadas e registradas pessoalmente pela pesquisadora com auxílio de intérprete nos casos de deficientes auditivos. A observação da linguagem e expressão corporal dos respondentes foi considerada devido a demanda de deficientes auditivos.

No capítulo adiante, os resultados encontram-se divididos por categorias. 


\section{RESULTADOS}

\subsection{Dificuldades cotidianas e a escolha do profissional}

A trajetória da maioria das pessoas com deficiência é difícil, afinal a sociedade não foi construída pensando neles e as adaptações e mudanças previstas em lei ainda estão desaceleradas. Os respondentes relatam inúmeras ações do cotidiano que se tornam constrangedoras, haja vista a tamanha dificuldade em se comunicar. Ao entrevistá-los foi percebida a grande dificuldade na comunicação relatada. As palavras que conhecem são limitadas e por vezes foi preciso explicar palavras como "trajetória" até mesmo para que a leitura deles fosse bem compreendida. Nos depoimentos que seguem pode-se verificar a rotina vivenciada:

[...] no caso a pessoa tem que falar de frente pra mim, tem coisa que é difícil entender quando fala, eu peço para explicar. (Respondente 1)

Falta informação para quem não escuta e a falta de interprete em palestras e demais ambientes prejudica. Não escutamos os alertas e isso provoca acidentes e é perigoso. O próprio curso oferecido pelo SENAC não tem intérprete profissional qualificado. É alguém que conhece mais não sabe de tudo de Libras. O intérprete da informações mínimas [...] se existe um questionamento em sala o intérprete não consegue explicar pergunta e resposta em tempo hábil. Me sinto prejudicada (Respondente 2)

No caso da deficiência auditiva a falta de intérprete em inúmeras ocasiões dificulta a vida cotidiana. Minha mãe fala pra eu ir ao médico sozinha, e eu pergunto como? Impossível. Ele não vai entender nada, nem se eu escrever (Respondente 4)

Foi observado fato de que a linguagem (tanto a de sinais quanto a escrita) utilizada pelos deficientes auditivos, tem uma diferença grande pela falta da gramática e pela limitação de palavras, um dos respondentes cita a necessidade:

[...] Tornar Libras mais accessível, pois parece que falamos outra língua com mesmo português, tenta aproximar ambas para não continuar com tanta distância e dificuldade em se comunicar (Respondente 3).

Essas dificuldades relatadas são bem específicas da deficiência auditiva, quanto as demais deficiências não foi notado preparo do ambiente para lidar com os outros tipos de limitações. Faltam rampas de acesso, espaço para 
transitar com cadeira de rodas, demarcação para acesso e informação para deficiente visual entre outros.

Apesar de a instituição fornecer cursos para pessoas com deficiência não foi percebido preparo do ambiente para recebê-los. Talvez por isso os contratados tenham sido escolhidos por motivo de melhor adaptação ao ambiente. $\mathrm{E}$ verifica-se a questão da deficiência "leve" tão procurada por aqueles que colocam anúncios em jornais em busca de profissionais decorativos para cumprir cotas ou mesmo que não aparente a deficiência, com vistas a dar continuidade à discriminação já existente, a qual prejudica e interfere diretamente no cumprimento das legislações.

Além das limitações já impostas por barreiras no cotidiano, pessoas com deficiência precisam vencer uma barreira que muitas vezes invisível o preconceito que começa dentro da família:

[...] desde pequeno fui criado assim, minha mãe é muito conservadora daquele pessoal mais antigo, e ela vivia falando "coitadinho, que não pode, que num sei o que", ai foi criando aquela psicologia e depois fui vendo que não era bem assim a coisa. Ela protegia muito. Ai eu acho que neste ponto me deu uma certa dificuldade, não da minha limitação mas as coisas psicológicas, a criação. A minha deficiência quase não se nota, só depois que eu falo "olha eu tenho essa e essa dificuldade" que vão notar mas mesmo assim depois que as pessoas ficam sabendo você nota que tem um pequeno preconceito. Antes de falar é normal, eu acho errado tem que ser tratado como uma pessoa comum mesmo porque isso não atrapalha (Respondente 6)

[...] A falta de apoio da família dificulta também a ter uma vida normal. Minha amiga surda foi incentivada a tirar carteira de motorista, ta noiva e na minha casa eles me olham e pensam que não sou capaz, não me estimulam, pelo contrario desmerecem e banalizam os sonhos e anseios [...] quero fazer faculdade, pós-graduação [...] (Respondente 4).

Percebe-se que a classe social dessas pessoas provoca uma influência drastica no conhecimento, na falta deste, e no preconceito vivenciado. Quando a deficiência passa a ser um obstáculo dentro de casa dificilmente essas pessoas serão encorajadas a buscar novas oportunidades. O medo afetará a auto-estima e tudo isso influência na busca por uma vaga no mundo do trabalho.

Não se pretende fazer caridade ao contratar pessoas com deficiência, mas, como toda contratação se objetiva o lucro. E para conseguir ainda mais espaço 
no mundo do trabalho as pessoas com deficiência precisam ser confiantes e mostrar a que vieram.

A sociedade ainda precisa ser educada para lidar normalmente com as pessoas com deficiência, não bastam as leis e as ações afirmativas é preciso conscientização.

A metade dos respondentes atribuem a vaga em que trabalham a um benefício que tiveram advindo da lei de cotas para as empresas:

[...] conseguiu o contrato na empresa por ser deficiente (Respondente 4)

[...] consegui a vaga de trabalho por ser deficiente (Respondente 5)

Assim em termos de benefícios [...] entrei na empresa através da deficiência. Sou contratado como deficiente por meio da lei de cotas (Respondente 6).

Por menores que sejam as iniciativas de se contratarem pessoas com deficiência, é preciso igualar as chances para todas as pessoas sejam elas cadeirantes, surdas, cegas ou com quaisquer tipos de limitações.

No próximo item será exposto o valor que o trabalho tem na vida de uma pessoa com deficiência.

\subsection{Significado do trabalho na vida do deficiente}

Segundo o entendimento de Nohara (2009), o trabalho confere sentido à vida, pois é símbolo de atualização e de realização, ao proporcionar condições para a afiliação e a vinculação do indivíduo a um grupo, torna-se fonte de experiências e de relações humanas satisfatórias. Proporciona condições para a aprendizagem e desenvolvimento de competências, garante a segurança e a independência financeira e contribui para a autonomia do indivíduo (NOHARA; ACEVEDO; FIAMME, 2009). 
Todos os respondentes demonstraram ter boa relação e gostar do trabalho:

Me faz bem, eu gosto do trabalho que eu faço (Respondente 1);

Gosta de ajudar, gosto de me relacionar com ouvintes e surdos porque vejo a cooperação. O grupo de trabalho entende e se comunica. Prazer! Experiência boa para a vida (Respondente 2);

Gosto muito do trabalho até porque eu já acostumei já e se eu ficar sem trabalhar, fico agoniado. Meu trabalho é essencial. Tirando as diversões e a igreja, trabalho também é muito importante (Respondente 6).

Quando o assunto é a empresa, eles se limitam a responder que é normal e que ela oferece o necessário para o cumprimento das atividades. Os contratados pelo programa Jovem Aprendiz acham que falta oportunidade e que as que existem são limitadas, a contratação destes é vinculada a um curso, ao final deste o contrato pode ser efetivado ou cancelado. O planejamento da empresa já trabalha em favor da rotatividade dos inclusos neste programa, pois o intuito é fornecer qualificação profissional e experiência, fazendo com que estejam melhor preparados para o mercado de trabalho que os espera, em um tempo determinado, dessa forma mais pessoas poderão ter a mesma oportunidade para iniciar sua vida no mundo do trabalho.

No caso dos contratados em regime de CLT ambos são registrados como prestadores de serviços gerais, mas já exercem função administrativa há algum tempo e não tiveram sua troca de função efetiva nem na carteira de trabalho e nem no crachá. Ao perguntar o motivo, da demora na promoção ambos não sabem responder, mas dizem ter promessas de que em breve isso acontecerá.

\subsection{Ações inclusivas}

A empresa Delta, possui uma área específica de ações sociais. Atualmente oferece cursos para pessoas com deficiência auditiva e visual nas áreas administrativas e de tecnologias. Mesmo não tendo seu ambiente completamente adaptado ministra treinamentos e esta cooperando em favor da sociedade. Assim 
como esta empresa, existem várias outras que fazem sua parte oportunizando conhecimento e trazendo para a realidade as pessoas com deficiência que vivem a margem da sociedade:

Eu acho que melhorou muito, nos dias de hoje, já foi pior né. Mas eu acho que pode ser melhorado. mais especializações mais cursos para estas pessoas, né, com deficiência, mais oportunidades no mercado de trabalho. Falta qualificação dessas pessoas. Abrir mais instituições para inserir melhor essas pessoas as comunidades. Acho que estas pessoas precisam ter um convívio melhor, porque acho que tem gente que conhece muito pouco de deficiente. Criam um parede entre ela e o deficiente, dizendo que "a o deficiente é um coitado". E na verdade num tem nada disso. Eu acho que tem provas que [...] nós que somos deficiente até nos destacamos. (Respondente 6)

O respondente reconhece a falta de qualificação. Mas já percebe melhoras em relação ao passado. Que por falta de conhecimento e legislação a pessoa com deficiência não era levada em consideração e era tratada como incapaz.

Estas pessoas precisam não somente de ações sociais, mas que a sociedade os enxerguem como pessoas produtivas e lhes dêem oportunidades de trabalho e qualificação profissional:

Dar a chance para as pessoas com deficiência, oportunidade para elas mostra que são capazes (Respondente 1);

Aumentar a oferta de cursos e treinamentos com intérpretes (Respondente 5) 


\section{CONCLUSÃO}

Este estudo teve o objetivo de realizar uma revisão bibliográfica e de campo acerca das dificuldades de inclusão de pessoas com deficiência no mundo do trabalho e expor de maneira mais próxima da realidade a sociedade real em que vivem. O caso foi vivenciado em uma empresa privada de Brasília, Distrito Federal, para o que, por questões éticas deixou-se de mencionar o nome real da organização e a denominando nesta pesquisa de "Empresa Delta".

Nesse sentido, com a indagação de um dos entrevistados, "E você acredita em um futuro melhor?" (Respondente 4), o qual termina a última entrevista do dia, ele tem uma postura divertida ao perguntar, mas descrente do que venha a acontecer. E com razão. Mesmo depois de tanto tempo e de criações de leis, as mudanças são muito sensíveis e não trazem resultados imediatos.

A necessidade do conhecimento e vontade de mudar a realidade foram a motivação deste estudo que objetivou demonstrar as experiências de pessoas com deficiência inclusas em uma organização privada. É preciso que reconheçam as limitações da pesquisa, pois foi realizada em uma só empresa e o número de respondentes não foi o total de pessoas com deficiência contratado pela organização.

Dessa maneira, acredita-se que o estudo possa colaborar e até estimular o debate sobre as ações inclusivas dentro de organizações privadas. E demonstrar que é preciso e possível mudar a realidade.

Os respondentes reconhecem suas limitações, mas acreditam que poderia ser melhor se houvessem mais oportunidades tanto dentro das empresas quanto de acesso ao conhecimento. Os cursos destinados a este público, em geral os restringe a funções básicas. Entretanto, como seres humanos eles sonham, sem limites!

O combate ao preconceito e à discriminação tem que ser algo efetivo, não se devendo mascarar a existência destes males, os quais acabam por piorar a vida de pessoas que já têm dificuldades em se adaptar à realidade que os exclui. Assim, a única forma de se vencer esta batalha é com o estudo e conhecimento, mas não 
restringi-los a cadeiras acadêmicas, e sim levá-los ao público. Fazer com que informações cheguem em todos os níveis sociais e de forma clara e coesa, sem modismo mas sim de maneira enfática para que a aceitação seja ampla e abrangente.

É nítido que pessoas com deficiência têm ganhando espaço mas falta o reconhecimento e a oportunidade para que essas pessoas possam se desenvolver dentro das organizações. É preciso acreditar e ir além. Tornar realidade a criação de uma sociedade igualitária e justa. 


\section{REFERÊNCIAS}

ALMEIDA, Luciana Alves Drumond; CARVALHO-FREITAS, Maria Nivalda de; Marques, Antônio Luiz, in Carvalho-freitas, Maria Nivalda de; Marques, Antônio Luiz (Org.). Trabalho e as pessoas com deficiência: Pesquisas Práticas e Instrumentos de Diagnóstico. Curitiba:Juruá, 2009. Cap. 3.

BRASIL. LEI No 10.098, DE 19 DE DEZEMBRO DE 2000. Estabelece normas gerais e critérios básicos para a promoção da acessibilidade das pessoas portadoras de deficiência ou com mobilidade reduzida, e dá outras providências. Disponivél em: <http://www.planalto.gov.br/ccivil/LEIS/L10098.htm> Acesso em: 15 ago. 2009.

. LEI No 8.112, DE 11 DE DEZEMBRO DE 1990. Dispõe sobre o Regime Jurídico dos Servidores Públicos Civis da União, das Autarquias e das Fundações Públicas Federais. Disponível:

<http://www.planalto.gov.br/ccivil_03/LEIS/L8112cons.htm> Acesso em 5 jul. 2009

. LEI No 8.212, DE 24 DE JULHO DE 1991. Dispõe sobre a organização da Seguridade Social, institui Plano de Custeio, e dá outras providências. Disponível em: <http://www.planalto.gov.br/ccivil_03/LEIS/L8212cons.htm> Acesso em 15 ago. 2009.

. LEI No 8.213, DE 24 DE JULHO DE 1991. DISPÕE SOBRE A FINALIDADE E DOS PRINCÍPIOS BÁSICOS DA PREVIDÊNCIA SOCIAL. Disponível em: <http://www.planalto.gov.br/ccivil_03/Leis/L8213cons.htm> acesso: 10 jul. 2009

. LEI No 8.666, DE 21 DE JUNHO DE 1993. Regulamenta o art. 37, inciso

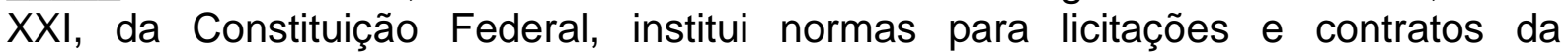
Administração Pública e dá outras providências. Disponivél em: <http://www.planalto.gov.br/ccivil_03/LEIS/L8666cons.htm> Acesso em: 15 ago. 2009

CARVALHO, Karina M. de, in CARVALHO-FREITAS, Maria Nivalda de; MARQUES, Antônio Luiz (Org.) Trabalho e as pessoas com deficiência: Pesquisas Práticas e Instrumentos de Diagnóstico. Curitiba: Juruá, 2009. Cap. 2.

DIAS, Luiz Cláudio Portinho - O panorama atual da pessoa portadora de deficiência física no mercado de trabalho. Disponível em:

<http://www.ibap.org/ppd/artppd/artppd_Icpd01.htm> Acesso em 25 ago. 2009

FLEURY, Maria Tereza Leme - GERENCIANDO A DIVERSIDADE CULTURAL: experiências de empresas brasileiras. RAE - Revista de Administração de Empresas, Jul./Set. 2000. Disponível em: <http://www.rae.com.br/artigos/377.pdf>, Acesso 25 ago. 2009.

GÜNTHER, Hartmut - Pesquisa qualitativa versus pesquisa quantitativa: Esta é a questão?. Psicologia: Teoria e Pesquisa, 2006, Vol. 22 n. 2, p. 201-210. Disponível em: <http://www.scielo.br/pdf/ptp/v22n2/a10v22n2.pdf>. Acesso em: 03 set. 2009. 
INSTITUTO ETHOS, 2000 - Como as empresas podem (e devem) valorizar a diversidade. Pesquisa 2000. São Paulo. Instituto Ethos, 2000. Disponível em <https://www.uniethos.org.brl_Uniethos/Documents/manual_diversidade.pdf >. Acesso em: 03 maio 2009.

2002 - O que as empresas podem fazer pela inclusão das pessoas com deficiência. Pesquisa 2002. São Paulo. Disponível em: <http://www.ethos.org.brl_Uniethos/Documents/manual_pessoas_deficientes.p df>. Acesso em: 20 jul. 2009.

SIQUEIRA, Marcus Vinícius Soares; OLIVEIRA-SIMÕES, Jussara Tatiana de., in Carvalho-freitas, Maria Nivalda de; Marques, Antônio Luiz (Org.) Trabalho e as pessoas com deficiência: Pesquisas Práticas e Instrumentos de Diagnóstico. Curitiba:Juruá, 2009. Cap. 11.

TANAKA, Eliza Dieko Oshiro; MANZINI, Eduardo José. O que os empregadores pensam sobre o trabalho da pessoa com deficiência? Rev. Bras. Educ. Espec, Mai.Ago. 2005, $v \quad 11, \quad$ n.2. Disponível em: <http://www.scielo.br/scielo.php?script=sci_arttext\&pid=S141365382005000200008> Acesso em: 25 ago. 2009. 